NEW SAFETY HYPODERMIC I NJECTOR.

BY J. WARD COUSINS, M.D. LoND., F.R.C.S., SURGEON TO TITE ROYAL PORTSMOUTII HOSPITAL.

During the last few years treat nent by hypodermic injection has been very generally aclopted in many forms of disease, and the number of remsdies introduced into the system by this method haz also steadly increased. Up to the present tims the hypoderm 'c syringe has been the only instrument employed by medical nien, and the great demand has resulted in the production of many new forms and many ingenious modifications. It is, however, a very general opinion that the syringe does not even now readily and conveniently fulfil all the purposes for which it is required in practice. It is easily deranged, very liable to accidental injury, and always requires very careful manipulation. In any form it must be considered a costly instrument, and certainly very troublesome to clean. When not in daily use it soon gets out of order, and the piston is a constant source of trouble. The washer shrinks or becomes worn and loose, so that the syringe does not work well, and often the operator discovers to his great vexation that the fluid, instead of entering the patient, gradually makes its appearance at the other end of the barrel. I am sure there are few medical men constantly employing hypodermic remedies who have not been disappointed by the faulty action and sudden failure of this delicate little instrument. The vast majority of practitioners, moreover, employ the same syringe for every emergency, and in the case of those who are fortunate enough to possess two such instruments it will be very frequently found that one of them at least is broken or otherwise out of order. The same hypodermic syringe is used for every patient as well as for every remedy, and in fact for every purpose for which it is required both in medical and surgical practice. Sometimes morphia has to be hypoder. mically injected for the relief of pain, then ergotine has to be administered in the same way during labour, and after that some other remedy must be introduced into another patient. At one time the syringe is charged with perchloride of iron for the treatment of nævus, and at another time it is used for injecting iodine into an indurated thyroid or other glandular enlargement. By the general use of a single instrument much extra labour and additional responsibility are always incurred. The same syringe when continually employed for a large number of potent medicines demands at the hands of the busy practitioner of the healing art the most scrupulous care in washing and cleaning after every operation. Of course this difficulty is readily overcome by obtaining a set of instruments, and by using a special syringe for every patient and for every remedy ; but this alternative invol " s considerable outlay, and certainly renders the administrat of hypodermic remedies an expensive form of treate and quite beyond the reach of a large class of patients. Whe syringe always requires care in its application : the eye must generally assist the hand, and the quantity of fluid injected must be regulated by the movement of the piston over an index. The piston is often furnished with a movable stop, and this is no doubt a valuable safeguard. Still it must be remembered that every addition involves extra attention, and that the stop itself has to be properly adjusted before every operation. The hypodermic injection of an active medicine and the due regulation of the dose always involve considerable responsibility, and for this reason it is never my practice to place the administration of any remedy by the syringe in the hands of attendants or friends.

The little instrument which is accurately represented in the figure is intended as a substitute for the hypodermic syringe, and I venture to hope that many of my professional brethren will find it a simple and economical contrivance, and well adapted for every medical and surgical purpose in which such an instrument is essential. The in jector consists of two parts : an elastic measuring ball and an injecting needle; the latter is provided with a boss, which serves for a handle during its introduction. It is conveniently furnished with a joint, so that the same needle may be adjusted on several measuring balls. The prefix "safety" is employed to indicate the important fact that its simple construction affords a valuable safeguard against accilent, and that it renders an overdose practically impossible. The measuring balls are made in different sizes, and each ball is capable of holding only a definite amount of fluid, the quantity varying from one to twenty minims. The number placed on the exterior of each ball expresses its capacity, so that by select. ing an injector the exact dose can be at once administered.

The instrument can be instantly charged by compressing the elastic ball and inserting the point of the needle or the open end of the joint into the fluid to be injected, and it is generally advisable to repeat this little operation two or three times to ensure the complete expulsion of air. It can be discharged slowly or rapidly under the skin, and this is of course regulated by the pressure of the thumb and finger. It can be washed out and cleaned in a moment, and it is no trouble to keep in order for any emergency. It cannot be broken by an accidental fall, which is too often the fate of the hypodermic syringe, and when it is worn out, it may be

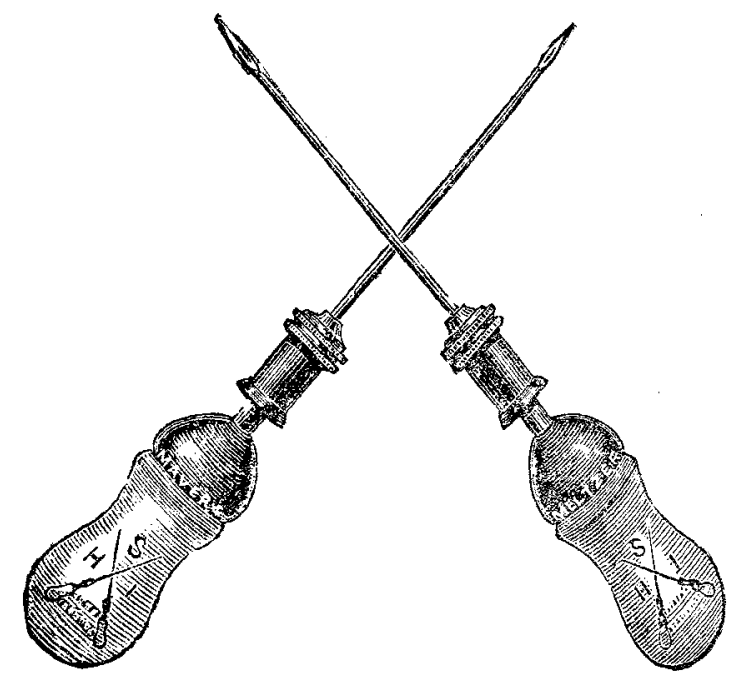

verv easily replaced. The injector can be used if necessary under the bedclothes, and as a mistake in the dose is impossible, the performance of the operation does not require the guidance of the eye. It has still another important quality, which cannot fal to increase its utilitythe cost is so moderate that a separate instrument can be used for every remedy as well as for every patient.

In conclusion, the safety hypodermic injector will serve many important surgical purposes, and it is a perfect substitute for the syringe in the treatment by injection of nævi and other tumours. It is made for me by Messis. Mayer and Meltzer, 71, Great Portland-street, and can be obtained from that firm in the form of a single instrument, or in a little case containing several injectors of various sizes. The surgical needle is furnished with three openings at the point to facilitate the escape of fluid into the tissues. Portsmouth.

\section{FATAL CASE OF LARYNGISMUS STRIDULUS.}

BY JOHN MCMUNN, L.R.C.P. ED., L.R.C.S.I., LATE DEMONSTRATOR OF ANATOMY, CARMICHAEL COLLEGE, DUBLIN.

ON May 5th, 1882, a woman sought advice for her little daughter, aged one year and nine months. The general health of the patient was good, but at certain times she lost her breath and had to struggle hard to regain it. There were three previous children, all of whom had died in infancr. The duration of disease in the present instance was three weeks; such was the mother's story. The child looked healthy, voice and respiration were normal ; the lower gum was swollen and tense over the sites of the temporarr molars. Finding here a probable exciting cause of what I believed to be laryngismus stridulus, I determined to lance the gums. As the knife grated on the subjacent tooth the child commenced to cry violently, but at the expiration of one long loud cry it became silent. Breathing was suspended. After the lapse of a couple of seconds a struggle for breath ensued, the face assumed a frightened look, the mouth was widely opened, the trunk and limbs were stiffened, the toes and fingers worked, while the inspiratory muscles were thrown into violent contraction, and signs of asphyxia rapidly developed; the face grew livid, drops of sweat stood on the forehead, the pulse grew feeble and small, while with widel dilated pupils the inturned and suffused eyeballs seemed to 
start from their orbits. Violent inspiratory efforts culminated in general convulsions. Soon all was still, the pulse vanished from the wrist, impulse and sound ceased over the heart, and general muscular reaction took the place of contraction.

Treatment. - The child was shaken, its face mopped with a wet handkerchief, its back and stomach slapped with the wet hand, attempts to excite vomiting were made, the tongue was drawn forwards, and the vapour of chloroform blown down the throat from the palm of the hand, when muscular relaxation took place; artificial respiration was carried out for some time, while endeavours were made to excite anew the heart's action. Tracheotomy was proposed early, but no reasonings would induce the mother to give her consent.

Remarks. - The tongue of a child is fitted to the arch of the palate; it breathes through its nose ; in crying the tongue is flattened, depressed, and drawn backwards. Laryngeal obstruction took place after a violent expiration, or at the commencement of an inspiration. Sudden falling of the epiglottis would be thus easily induced, this would induce spasm in the irritable muscles which guard the entrance of the windpipe, while further inspiratory efforts would tend to perpetuate obstruction, especially in the yielding larynx of a child.

Park-lane-terrace, $w$.

\section{9 atirut}

\section{HOSPITAL PRACTIE, BRITISH AND FOREIGN.}

Nulla autem est alia pro certo noscendi via, nisi quamplurimas et morborum et dissectionum historias, tum alioram tum proprias collectas habere, et inter se comparare.-Monga MNI De Sed. et Caus. MTorb., lib. iv. Procemium.

\section{ST. BARTHOLOMEW'S HOSPITAL.}

THREE CASES OF ACUTE RHEUMATISM COMPLICATED WITH PERICARDITIS AND PLEURO-PNEUMONIA ; REMARKS.

(Under the care of Dr. SouTuEY.)

THe following notes and remarks illustrate the superven. tion of some grave complications in acute rheumatism :-

CASE 1.-Letitia $\mathbf{T} \longrightarrow$, aged sixteen, a machinist, single, an anæmic strumous-looking girl, was admitted on Oct. 5th with rheumatism and pericarditis, having been laid up at home with articular rheumatism since September 28th (eight days). This was the first attack of rheumatism she had had, and with the exception of scarlet fever and whoop ing cough she had never been laid up before.

Condition on admission.-Perspiring profusely; temperature $102 \cdot 6^{\circ}$. Decubitus dorsal ; no pain in chest, no cough; she lay very still quite low in bed; mind clear. Tongue white and furred; breath foul ; bowels costive. Micturition natural, urine high coloured, otherwise normal. Catamenia just ceased, always regular. Heart apex beat in the fifth interspace below the nipple. Thrill felt with systole, and friction rub heard all over the cardiac region. Pulse 144, soft. Lung; presented no abnormal sounds or dulness. Respiratory sounds clear; respiration 90. Abdomen natural Large joints, as shoulders, hips, and knees, were more affected than the small ones.

Treatment by twenty grains of salicylate of soda, and seven drops of tincture of opium every four hours. The temperature fell the following morning to $98.6^{\circ}$, and only rose to $1002^{\circ}$ on that and the next day. Her pains promptly subsided. There was no anxiety; no restlessness. On the thirteenth day of the rheumatism the temperature fell to normal and remained so for three days, but the friction rub became less distinct, and the precordial dulness increased. She was very drowsy, but woke up to take her nourishment. The opiate was now diminished, and the salicylate given less frequently. There was effusion enough to produce marked præcordial dulness on the twelfth day of illness, and contemporaneously, or nearly so, bronchial breathing and bronchophony were noticed at the root of the right lung, and over more than two-thirds of the left lung. The dorsal position was maintained. Temperature $102 \cdot 6^{\circ}$; pulse 120. Symptoms of more active implication of the left pleara were noticed on the nineteenth and twentieth days of the illness. Pain stitchlike and friction rub. At the same date the dislocation of the heart's apex upwards and outwards, and its disappearance from the chest-wall, too, were well marked. The heart's impulse being felt on the level of the mammæ, she was advised to make some effort herself to lie on both sides alternately, and was directed to be propped by pillows into such position. Slight regophony was noticed over the area of bronchial breathing.

Treatment. - Twenty grains of salicylate of soda, and five drops of tincture of opium, every four hours, were repeated. Her temperature fell gradually from the nineteenth day of illness, and her pulse inoproved. She has been able to sit up in bed and do needlework. Since the twenty-fourth day her pulse has been from 74 to 84 ; respiration 24 ; and temperature below normal. Heart-sounds have been clear, and no friction sound has been heard over front of chest. She has had no fever and no cough, but there is still a friction sound synchronous with respiration behind over left lung, some dulness and evidence of feeble air entry at base of lower third of left lung. She entered upon convalescence on the twenty.fourth day of her illness.

The facts in evidence of the course of this patient's disease ar e:-Pericarditis ; pericardial effusion ; imperfect air entry into lower lobe of left lung. Bronchial breathing; no rusty expectoration, followed by lateral and posterior friction rub and slight ægophony; rheumatic pleuro-pneumonia, with slight pleuritic effusion. Her temperature fell from $1026^{\circ}$ to $994^{\circ}$ on the ninth day of her illness, pericarditis notwithstanding, and it was not till ten days later that it rose at all high again, $100 \cdot 6^{\circ}$ and $101^{\circ}$, when she had some fever from her left pleuro-pneumonia. This febrile disturbance lasted four days, and she has since convalesced with one slight relapse.

CASE 2. - Eliza P_ aged forty-six, and fairly nourished, prematurely grey-haired woman, single, entered on her menopause at the age of forty-one. She had small-pox at nine years old, and her first attack of rheumatism at nineteen, which laid her up for some weeks; second attack at the age of forty-five, during which she was laid up six weeks. The present illness began three weeks before ber admis sion by swelling and pain in her left foot, which shifted to her shoulders, calves, knees, and lastly wrists. She was feverish, had no appetite, and the pain made her feel sick.

Condition on admission. - Sept. 9th: Lying flat on her back, unable to help herself; all the joints of her arms stiff and painful; both wrists swollen; the right red and very tender. Knees and right hip-joint very painful ; ankles swollen, red, and hot to feel. Pulse 108; respiration 18; temperature $100^{\circ}$ to $101^{\circ}$. Bowels open four times freely; tongue coated with usual thick white fur, and inclined to dry; urine high-coloured; skin moist ; pupils large.

Physical examination. - Fauces and abdomen yielded negative signs: heart impulse feeble, apex-beat indistinguishable, systolic apex murmur; præecordial dulness increased over both lungs before and behind : rhonchus and catarrhal sounds, but resonance un ed. She was placed on the usual slop dietary, and tr ent by salicylate of soda was pushed to salicylism, an ent established in twenty-four hours.

Course and progress.-Three dar: ater her pains were gone; but she complained much of her head, and her cough was troublesome. She took her nourishment fairly, but slept very little. Pulse 78 , small and weak; respiration 20. Good resanance over lungs, front and back, and fewer moist sounds. Joints still swollen, and painful upon least movement. General condition extreme weakness; lies always in the same posture. After she had been under treatment twelve days, and therefore on about the thirty-third of her illness, we noticed that her pulse had risen to 96 , respiration to 36 , and temperature, which had gradually fallen to below normal, rose to $1000^{\circ}$. Her cough was more troublesome, and she had a relapse of pains. Pericardial friction was now audible all over the cardiac region in front, and the dulness increasing. The following day the effusion was obviously increased and her temperature went up to $104^{\circ}$, but no physical sigas as yet of pressure upon the lungs were observed. The relapse of pains lasted for the usual three days; improved on the fourth, when she slept well without any opiate. But we observed marked dulness on percussion on this the thirty-seventh day of her illness at the base of the left lung. Pericardial friction and pracordial dulness still well marked in front. Since her pericarditis had been ascertained beyond 